Preprint. Final version appears as:

Morgan, R., Wiltshire, P., Parker, A. \& Bull, P. (2006) The Role of Forensic Geoscience in Wildlife Crime Detection. Forensic Science International. DOI 10.1016/j.forsciint.2006.06.045

\title{
The Role of Forensic Geoscience in Wildlife Crime Detection
}

\author{
Ruth M. Morgan ${ }^{1}$, Patricia Wiltshire ${ }^{2}$, Adrian Parker $^{3}$, Peter A. Bull ${ }^{1}$ \\ University of Oxford, $\mathrm{UK}^{1}$, University College London, $\mathrm{UK}^{2}$, Oxford Brookes \\ University, $\mathrm{UK}^{3}$
}

Communicating author: Ruth Morgan

Ruth.morgan@ucl.ac.uk

Tel: +442031083037

Fax: +44 2031083088 


\title{
The Role of Forensic Geoscience in Wildlife Crime Detection
}

\author{
Ruth M. Morgan ${ }^{1}$, Patricia Wiltshire ${ }^{2}$, Adrian Parker $^{3}$, Peter A. Bull ${ }^{1}$ \\ University of Oxford, $\mathrm{UK}^{1}$, University College London, $\mathrm{UK}^{2}$, Oxford Brookes University, $\mathrm{UK}^{3}$
}

\begin{abstract}
The increase in both automation and precision in the analysis of geological materials has had significant impact upon forensic investigations in the last 10 years. There is however, a fundamental philosophical difference between forensic and geological enquiry. This paper presents the results of forensic geoscientific investigations of three cases of wildlife crime. Two cases involve the analysis of soils recovered after incidents of illegal badger baiting in the United Kingdom. The third case involves the illegal importation of Eleonora's Falcon (Falco eleonorae) into the United Kingdom from the Mediterranean. All three cases utilise the analysis of soils by a variety of physical, chemical and biological techniques. These involve mineral and grain size analyses, cation and anion compositions, $\mathrm{pH}$, organic content and pollen analysis.
\end{abstract}

The independent analysis undertaken by specialists in each of these three main fields conclude firstly, that there is a significant similarity between sediments taken at the crime site at both badger setts and with sediments recovered from various spades, shovels and clothing belonging to suspects and secondly, that the soils analysed associated with the removal of the falcon eggs in the Mediterranean contained characteristics similar in many respects to the soils of the breeding areas of Falco eleonorae on the cliffs of Mallorca. The use of these independent techniques in wildlife crime detection has great potential given the ubiquitous nature of soils and sediments found in association with wildlife sites.

Key words: Forensic Geoscience; Eleonora's Falcon, Badger Baiting; soil and sediment; pollen; quartz 


\section{Introduction}

Forensic geoscience is a rapidly developing branch of criminal investigation utilising the analysis of rocks, sediments and soils by studying the physical, chemical and biological components of a sample. The rapid development of analytical techniques, machinery and to some extent automation, enables very detailed characteristics of a sediment to be identified from large numbers of samples. Soils and sediments are now routinely analysed to compare crime sites with items belonging to a suspect and their vehicles.

The increased detection capabilities of analytical techniques enables at least parts per million of a chemical, or individual sediment grains, which are nanomicrons in size, to be identified. The early work of Edmond Locard [1], where he implied that 'every contact leaves a trace', is now more pertinent than ever before.

This paper provides three examples of the application of some forensic geoscience techniques in the investigation of wildlife crime. Two cases involving badger-baiting and one case of illegal importation into the United Kingdom of an endangered species of bird, are presented showing how complementary analytical techniques were employed to compare samples taken from the scenes of the crime with those taken from belongings of suspects (see also [2]). The interpretation of the results are included, mindful of the philosophical and practical restraints that should be employed in such analyses. 


\section{The Philosophy and Nature of Forensic Geoscience}

In order to provide accurate forensic geoscientific interpretations from the analysis of sediments and soil, it is important to recognise the difference between geological and forensic procedures. A plethora of techniques can be found to analyse the physical, chemical and biological components that make up sediments and soils. Whilst many of these techniques provide a very accurate, experimentally reproducible series of data, they imply an advantage of the capability of being automatically analysed in large batches. The primary aim of geological analysis is often that of palaeoenvironmental and geological reconstruction. The area of investigation can range from microscopic to global in scale. Forensic investigation involves the comparison of samples taken from a crime scene with those samples recovered from a person or their belongings. Sometimes the forensic aim is that of determining the provenance of material. The forensic geoscience rationale is to exclude a sample from a comparator sample by means of their physical, chemical or biological characteristics [3] [4]. It is very rare in forensic geology to be able to 'match' two samples; a physical fit of two broken rocks is indeed an unusual occurrence. By their very nature soils and sediment vary not only within a spatially restricted site, but they may also contain similar characteristics to soils and sediments from other sites. This does not stop some practitioners from attempting to find matches between samples [5] [6], or at least to strive to find similarities [7].

When samples are analysed, the resultant interpretation may be to exclude, not match samples. Analysis may provide descriptive qualities of the soil or sediment which may, or may not, be diagnostic. If two samples possess similar descriptive attributes 
in any number of physical, chemical or biological characteristics, they may well have derived from one common source, but equally they could have derived from separate sources of similar characteristics. Therefore, it is very important when interpreting the results of soil and sediment analyses that due care is given to the exclusion of samples and that the samples which show very similar characteristics are viewed in the context of the distinctiveness or rarity of their particular attributes. Kirk ([8] p2) stated 'physical evidence can not be wrong; it can not perjure itself; it can not be wholly absent. Only in its interpretation can there be error'.

There is a further difference between geological and forensic analyses which is necessitated by the relative quantities of material typically available. Geological analyses often involve quite large amounts of material whereas forensic analysis is often undertaken, particularly from anthropogenic sources, on only trace amounts of soil or sediment. Thus the whole gambit of procedures and techniques highlighted by Palenik (as presented by Murray and Tedrow [9]) cannot usually be fulfilled.

It is abundantly clear that wherever possible a range of independent techniques are required before meaningful interpretation of results can be provided. (The cases presented in this paper utilise biological and pollen techniques together with physical and chemical attributes of the soil and sediments with particular reference to mineralogy). However, the use of certain tests that are used widely in geological analysis do have inherent problems for forensic enquiry. Analytical techniques which require the homogenisation of a sample prior to analysis can prove very problematic for the forensic scientist [10]. Standard chemical analysis techniques which require the reduction of a sample to a solution will inevitably homogenise the whole sample. 
Thus, the interpretation of atomic absorption spectrophotometry (AAS) and inductively coupled plasma spectrometry (ICP) analysis, whilst potentially capable of distinguishing between comparison samples, is unable to determine whether an observed analytical difference is caused by mixing of sediment or contamination that has occurred prior or subsequent to the forensic event. False-positive or falsenegative associations or exclusions can not be checked and interpretation will inevitably be compromised. Similar homogenisation occurs when samples are automatically colour graded (e.g. using a spectrophotometer) following the pulverisation of a deposit into a uniform pellet. Once again, contamination or mixing can not be taken into account and so meaningful comparison is once again compromised. Finally, similar problematic interpretations may occur following grain size analysis, although as will be seen in this paper, given sufficient care, results can prove illuminating.

\section{Case Studies}

\subsection{Suspected badger (Meles meles) baiting identified by comparison of} material taken from two spades with material from the crime scene

\subsubsection{Mineralogy, grain size and quartz grain surface texture analysis}

The physical characteristics of two soil samples taken from the badger sett site (surface and depth) were compared to the material taken from two spades (spade 1 and spade 2; figure 1). Munsell colour analysis indicated that all four samples were designated 2.5YR 4/6, which approximates a reddish colour and is one of the categories of the 80 or more recognised by the Munsell system of classification. Of 
course, colour can only work as an exclusionary and descriptive technique, since the homogenisation required to prepare the sample would inevitably fail to identify mixing and contamination around a forensic incident. Thus, false-positive or negative associations can not be tested for falsehood [10].

Chemical appraisals of the $\mathrm{pH}$ and conductivity of the soil samples together with AAS and Dionex analysis to identify cation and anion concentrations of the most common elemental types were undertaken. Results are presented in figures 2 and 3. Given the general variability even within one soil type, the variances identified from comparison between the two spades and the two site samples suggested that the samples could not be excluded from having derived from the same or similar source. Indeed, the range analysed was broadly the same with only a small variance between comparator samples such as would be found in the natural fluctuation within one soil type. It is important to note that this simple analysis can not exclude the two spade samples and the site samples from having derived from the same or similar source.

The four samples were analysed by binocular microscopy to obtain a broad indication of the presence of detrital minerals and other debris. All samples showed assemblages of quartz, rounded iron rich nodules, small agglomerates of reddish clay and light coloured root fibres, together with small amounts of wood and organic debris (see figure 4). The limited sand-sized soil content was striking as the samples were remarkably lacking in the normal detrital mineral assemblages. No further binocular analysis was undertaken. 
Grain size analysis was undertaken on the two samples taken from the badger sett and soil recovered from the two spades. The analysis by laser granulometry showed that the grain size distribution curves were very similar to each other, with the exception of the sample analysed from the front of spade 2 (see figure 5). The discrimination of one subsample from a source sample could be explained with reference to contamination by materials previously deposited on the spade. The technique has no means of differentiating such contamination, and as such is often used purely as a descriptive mechanism and usually only as an exclusionary tool. Similarities can be noted; no more than that.

Finally, analysis was undertaken to investigate the surface grain textures of individual quartz particles. A substantial literature has been built up in international journals relating the textures of individual grains of quartz, viewed often under high magnification by a scanning electron microscope [11]. In geological investigations, forty or more textures have been identified and all can be attributed to geological processes and conditions. Such detail enables samples to be compared and exclusions to be identified. This generally ubiquitous mineral, found in most soils, contains grain types (these are an amalgam of suites of grain surface features) that can vary dramatically from site to site. Bull and Morgan [12] identify that there are only a very discrete number of quartz grain types found in each sample, taken across England $(\mathrm{n}=$ c.1000 from which a database was constructed) and that it is possible to compare comparator grains to sample grains, and if the quartz grain types were different, then they could be excluded from having derived from the same source. 
Samples taken from both the surface and at depth at the badger sett site, contain three main types of quartz grain textural groupings. This combination of groups is not found in any of the thousand sample locations in England. One particular grain texture found on the grains taken from both the surface and depth samples at the badger sett is distinctive, being found on only $1.93 \%$ of the 30,000 quartz grains in the database. This grain type; an elongated euhedral overgrowth with terminations is pictured in figures $6,7,8$ and 9 . This makes a very significant marker grain and is found from soil samples taken from both the front and back of the spades. Indeed, all the samples from the two spades contain the same three grain type assemblage as found at the badger sett.

It could be reasonably expected that in employing the above techniques, samples of soil taken from the two spades would be able to be excluded from the source samples taken from the badger sett, if significant differences had been found. The techniques employed contained techniques not dependent on each other (colour, conductivity, $\mathrm{pH}$, and chemical content could reasonably be argued to have some dependent characteristics, although these are independent of quartz grain surface texture analysis and to some extent grain size analysis) and in conclusion they can not exclude the samples from having derived from the same location. Indeed, the similarities in analysis in all samples in this case is noted and considered to be very significant.

\subsubsection{Palynology}

Palynological analysis was undertaken on soil samples taken from the two spades (spade 1 and spade 2; figure 1) and from two areas of a badger sett which had been dug in order to access the animal. The results were obtained following standard 
methods, laboratory sampling, identification and counting following that of Bennett et al. [13], Moore et al. [14] and Stace [15]. No attempt was made to differentiate taxa if there was any room for doubt in identification, many taxa were identified only to family or generic level. The standard published keys and modern reference materials outlined in the references above and by Edwards [16] and Anderson [17] were utilised. The percentage results for each of the four samples are presented in figure 10, and the data are arranged according to various groups: fungal/algal remains; trees/shrubs/climbers; spore producers; and herbs.

If a spade has dug into a soil, there will be both shallow and deeper soil represented on the blade and it is important therefore, to have some knowledge of the palynological nature of the soils in the upper and lower levels of the profile. In most instances, soil formation (pedogenesis) is a dynamic process and organic materials are constantly added and decomposed. Depth may be equated with age and as such the amount of decay or corrosion of organic material such as pollen grains and spores is largely a function of their residence time within the soil. The longer they have been present, the more likely they are to be decomposed and difficult to identify.

It is important to note that some palynomorphs are relatively resistant to decomposition whilst others are very vulnerable. Thus, deeper soils tend to have palynological profiles somewhat biased towards robust taxa and higher numbers of decayed and unidentified palynomorphs would be expected. Surface and shallow soils have palynological profiles which are more representative of extant vegetation at any location. Figure 10 shows that the numbers of unidentified palynomorphs are highest in the site sample taken at depth and this reflects their residence time within 
the soil. The percentage for corroded and decayed pollen and spores was $32.1 \%$ of the total count compared to only $1.6 \%$ in the surface soil. This result is what is to be expected; the shallow sample had larger numbers of easily identified palynomorph taxa and a lower number of corroded and unidentified ones than the deep sample.

When the proportions of the various taxa are reviewed from the two soil samples from the sett, it can be seen that there were much higher values of Alnus (alder), Quercus (oak), Tilia (lime) and Caluuna (common heather) in the lower soil than the upper. These taxa are robust and tend to be recognisable after relatively long residence times in the soil. Most other taxa had lower percentages in the lower sample and this is a function of decomposition. It must also be remembered that vegetation can change with time so that a deep soil will be more representative of vegetation that might be different from that present at the site today.

Although one sample was taken deep within the soil profile and the other from nearer the surface there was sufficiently close similarity to recognise that they were from the same soil profile (figure 10). The similarity between these two controls was also confirmed by the background debris and character of the fungal remains as well as the pollen and plant spore assemblages. There is little doubt that the profile represents a largely open habitat but that deciduous trees and shrubs and Pinus were growing in the catchment.

Figure 10 also demonstrates the close similarity between the pollen assemblages recovered from soils taken from the two spades. They have very similar ranges of 
palynomorphs, indeed, approximately $66 \%$ were in common and the proportions of most taxa were within a similar range.

It must be remembered that soil is a complex matrix and that there will be a certain degree of spatial heterogeneity in palynomorph distribution. An identical 'match' could never be expected, either between the two spades or the spades and the site samples. There were for example, traces of Picea (spruce), Salix (willow), Tilia (lime) in the soils from the sett that were not found on the spades. When so few pollen grains of these taxa were present in the original soil, it is not surprising that some failed to be transferred to the spades. The spades might have been used for other work so that mixed assemblages (contamination) might be present. A garden plant such as Ligustrum/Syringa (privet/lilac) was found on spade 1 but not on spade 2, and again this is not surprising because as they are insect pollinated their pollen is relatively rare in soils, even in close proximity of the parent plant.

Overall, the taxa found on the spades bear closest resemblance to those taken from the upper soil of the badger sett, although many of the taxa present from the soil taken at depth in the badger sett were also found on the spades.

In conclusion, if the sett were not the source of the soil then to achieve the palynological profile observed on the spades, there must be a place offering identical conditions. Such similar sites, the existence of which is theoretically possible, has yet to be encountered by the authors. 


\subsection{The illegal importation into the UK of Eleonora's Falcon (Falco}

Eleonorae)

A man was detained in southern England being in possession of two young falcons (Falco Eleonorae). Subsequent searching of his house revealed a bag containing various items of climbing kit, including a 'new' rope which was dirty only over the initial length of $19.9 \mathrm{~m}$. The rest of the rope was clean and looked brand new since it contained paper labels which were fresh and not worn by use. The dirty rope was washed to retrieve soil particles and the mixture was concentrated by centrifuge for analysis. The soil was markedly red in colour. This sample was compared with four samples taken from locations on the island of Mallorca, where it was known that these birds bred in the wild.

Binocular microscope analysis of the soil taken from the rope was found to contain plant debris, limestone and calcite particles, shell fragments and quartz grains together with a fine matrix of red soil. Scanning electron microscopy of the same soil material derived from the rope revealed two main types of quartz grain surface texture assemblages (see the case above for background details). The quartz grains showed some grains which were very blocky and angular and seemed to have derived from the in situ breakdown of a larger quartz conglomerate pebble deposits. There was also a distinctive quartz grain with well formed euhedral plates, some edges of which 
showed no edge abrasion whatsoever (this implies near source provenance of the material from a diagenetic sandstone lens).

The soil from the rope provided an unusual bi-modal grain size distribution with a median size of 8.5 microns, a clay fraction of $14.7 \%$ and a silt fraction of over $83 \%$. Chemical analysis (AAS and dionex) of the same soil indicated that the fine grain material originated from limestone redzina type soil with large amounts of sodium chloride. Allied to this chemical analysis was pollen identification which identified the presence of pine, fir, oak, grass and pistachio. Furthermore, SEM analysis also identified the presence of micritic calcite grains and a large number of diatom fragments. Since the pollen assemblage contained palynomorphs not found within a British context, overseas origins of the material taken from the rope could be sought.

Soil samples were subsequently collected in four sites in Mallorca in areas known to be the type of habitat that Falco Eleonorae would find suitable as a breeding area. All four samples were subjected to the same analytical tests to include binocular microscopy, scanning electron microscopy of quartz grain surface textures, grain size analysis, basic cation and anion chemical analysis and pollen analysis.

All four samples contained the same general materials identified from the material taken from the climbing rope, whereas scanning electron microscopy of the quartz grain surface textures was able to exclude two of the samples as having been the source of the soil found on the rope. Grain size analysis, although somewhat of a descriptive technique, was able in this case to identify that the statistical parameters of the grains found in one of the two remaining samples were so different to that of the 
characteristics of the soil taken from the rope that it was extremely unlikely that they both derived from the same source.

It was therefore, possible to exclude the soil from three potential breeding sites in Mallorca as having been the source of the soil recovered from the rope. It was not possible to exclude the remaining site sample as having been the source of the soil from the rope. This evidence contributed towards a guilty verdict and the first custodial sentence imposed for such a crime committed in Britain.

\subsection{Suspected badger (Meles meles) baiting identified by comparison of materials taken from boots and spades}

A man was arrested in a suspected case of badger-baiting close to a badger sett that had been dug up. Two spades were seized from his vehicle, as were the boots that he was wearing, which were caked in mud. A soil sample was taken from the badger sett to compare with the soil recovered from the boots and spades.

The sample from the badger sett was taken from a very disturbed site, so in the laboratory, ten subsamples were taken from this bulk sample (of approximately $1 \mathrm{~kg}$ ). This was to account for any within sample variance that may have existed through the different horizons of the soil profile that had been incorporated into the original bulk sample. Each spade was divided into 20 specific areas and a soil sample taken from each point. The boots were treated in a similar manner and it was possible to take 10 samples from the right boot and 14 from the left boot. 
A series of physical and chemical analytical techniques, were undertaken to compare the soil samples taken from each exhibit and the soil taken from the badger sett site.

Using the Munsell colour classification system, samples from the sett, boots and spades were designated colour codes, and these were all found to be within a very similar range. The $\mathrm{pH}$ values of these samples were again all within a similar range, with the possible exception of spade 1. A measure of the dissolved solids in distilled water was also undertaken by way of measuring the conductivity of these soil samples. The soil samples from the sett and spades had similar readings in the range 215-220 $\mu \mathrm{S}$, while the soil samples taken from the boots had higher conductivity values. All of these results are presented in summary form in figure 11.

Binocular microscopy of all the soil samples revealed a very distinctive assemblage of particle mineralogy and petrology as shown in figure 12. The assemblages found in each sample are similar to each other, and are noteworthy due to the small number of constituents present. These assemblages are of very local origin and their presence in all of the samples analysed can be deemed significant. It is not possible to exclude the soil taken from the spades or the boots as having derived from the same source as the soil sample from the badger sett. In addition, a number of black and white hairs were found in some of the samples taken from spade 2 and from both boots. These were subsequently examined by binocular microscopy, and found to be elliptical in cross-section, black and white in colour, and in some instances to have black and white bands. These were identified as badger hair (Meles meles) ([18] [19] [20]). 
Simple chemical analysis was undertaken on the samples using AAS and Dionex as outlined in the previous case. The results are presented in summary form in figure 13. As found previously, the range analysed was broadly the same for all samples with only a small variance between comparator samples such as would be found in the natural fluctuation within one soil type. Again, this simple analysis can not exclude the two spade samples or the boots and the site samples from having derived from the same or similar source.

There was sufficient sample to undertake particle size analysis (using a CILAS 920 laser granulometer) on all 10 samples from the badger sett site sample, 11 from spade 1, 10 from spade 2, 3 from the right boot and 1 from the left boot. Results are presented in figure 14. The analysis of the sett site samples provided two distinctive grain size distribution curves. One set of distribution curves produced from analysis of the soil from spade 1 revealed a curve similar to one of the curves from the sett site soil samples, while the samples analysed from spade 2 produced the two distinctive curves produced by the sett site soil samples (in-depth discussion of these results can be found in Morgan and Bull [10]). The materials analysed from the boots, whilst having some broad similarities to the grain size curves produced from the soil samples taken from the sett site, can be excluded from having derived exclusively from the same source as the materials at the sett site. It would appear that there was some 'contamination' or mixing of soils from different sources on the boots. This admixture is not surprising due to the nature of footwear and highlights the necessity for great care to be taken in the interpretation of results produced from techniques that require homogenisation of the sample prior to analysis. 
Finally, scanning electron microscopy of the soil samples was undertaken to assess the quartz grain surface textures (see section 3.1 for technique overview). Samples taken from the badger sett site proved to be predominantly quartz which were comprised of three main quartz grain textural groupings [12]. This combination of textural groupings is not found in any of the thousand sample locations found in the paper above and so can be excluded as having derived from any previously sampled source in Britain.

The predominant quartz grain textural group comprised quartz sand grains with evidence of diagenetic sandstone origins with subsequent late grain indentors caused by free grain collision, probably in a low energy sub-aqueous environment (such as a river) (see figure 15). Together with this predominant grain type were quartz grains which contained small authigenic euhedral quartz overgrowths produced during diagenesis of the original porous host sandstone (figure 16). A third grain type comprised a high relief angular grain with large conchoidal fractures and breakage blocks which exhibited only slight chemical edge rounding (possibly caused by pedogenic agencies). Although not the remit of this forensic investigation, it could be supposed that in a geological provenance reconstruction all three samples may be considered to have derived from an initial parent rock in the vicinity of the badger sett. Similar tripartite textural suites were found on quartz grains taken from soil samples obtained from both the right and left boots. It is not possible to exclude the quartz grains studied in this analysis from having derived from a similar or the same source. 
It could reasonably be expected that in employing all of the above techniques, that samples could be excluded from the badger sett site if significant differences had been found. The techniques employed in this case did not involve variables that were dependent upon each other and therefore the similarities in analysis of all samples in this case is noted and the samples can not be excluded from having derived from the same or similar source.

\section{Conclusions}

This paper presents the results of the investigation of three different wildlife crimes using geoforensic analysis. A number of important points have arisen from these simple cases that need to be viewed within the context of the philosophical framework outlined at the beginning of this paper.

1. There is a fundamental difference between the philosophical approach in geomorphological and geological analysis and that of the more Bayesian attitude necessarily adopted in geoforensic analysis. This approach is fundamentally lacking in some of the more recent cases published in the literature.

2. Care must be taken in choosing the analytical techniques, which may be appropriate for geological investigations, but must be used with extreme caution in forensic applications. Of course as many techniques as possible should be employed, but this is often determined by the quantity of sample rather than the philosophy of requirement. If techniques employed compared variables which are to lesser or greater extent dependent upon other variables 
which are also analysed, then extreme caution should be exercised. This is not always the case. An allied problem in forensic analysis is that of the contamination of a comparator sample before or after the forensic event. If analysis, no matter how detailed, complex and data producing requires that the sample be homogenised (by grinding or solution or both), then the associated results, be they positive or negative, can not be tested using these techniques and thus the authenticity of any association is gravely compromised.

3. Simple analytical techniques can separate out samples providing exclusions almost as efficiently as some of the more detailed high powered analytical techniques. Machine sophistication is not proportional to significance of association or exclusion.

4. There is no substitute for visual inspection and visual guiding of analytical methods. Automation of analyses does not result in inaccurate results, just the possibility of inaccurate interpretation. There is no room for untested assumptions and interpretations in forensic geoscience.

\section{Acknowledgements}

The authors would like to acknowledge discussion and comments with Guy Shorrock, RSPB, Chris Jackson, Geoff Calvert and Matthew Morgan. RM acknowledges financial support from the Bruce, Julia and Mortimer May Senior Scholarship at Hertford College Oxford. 


\section{References}

[1]Locard, E. Analyses of dust traces parts I, II and III. American Journal of Police Science 1 (1930) 276-298, 401-418 and 496-514.

[2]Shorrock, G. Wildlife Crime: a guide to the use of forensic and specialist techiniques in the investigation of wildlife crime. 88pp (www.defra.gov.uk) 2005

[3]Walls, H.J. Forensic Science. London: Sweet and Maxwell, 1968, p22.

[4]Bull, P. A., Morgan, R. M., Wilson, H. E. and Dunkerley, S. Multi-technique comparison of source and primary transfer soil samples: an experimental investigation' by D Croft and K Pye. A Comment. Science and Justice 44(3) (2004) 173-176

[5]Pye, K and Croft, D. J. Forensic Geoscience: introduction and overview. In Forensic Geoscience: Principles, Techniques and Applications. Geological Society, London, Special Publications, 232 (2004) 1-5.

[6]Pye, K. Forensic Examination of rocks, sediments, soils and dusts using scanning electron microscopy and X-ray chemical microanalysis. In Forensic Geoscience: Principles, Techniques and Applications. Geological Society, London, Special Publications, 232 (2004) 103-122.

[7]Blott, S. J., Croft, D. J., Pye, K., Saye, S. E. and Wilson, H. E. Particle size analysis by laser diffraction. In Forensic Geoscience: Principles, Techniques and Applications. Geological Society, London, Special Publications, 232(2004) 63-73.

[8]Kirk, P. L. Crime Investigation ( $2^{\text {nd }}$ ed) New York: Wiley. 1974, p2

[9]Murray, R. C. and Tedrow, J. C. F. Forensic Geology. Prentice-Hall, Inc, 1992.

[10]Morgan, R. M. and Bull, P. A. The use of particle size analysis of sediments and soils in forensic enquiry. Science and Justice in press

[11]Bull, P. A., Whalley, W. B. and Magee, A. W. An annotated bibliography of environmental reconstruction by SEM 1962-1985. BGRG Tech. Bull.,35 (1985)

[12]Bull. P. A. and Morgan, R. M. Sediment Fingerprints: A forensic technique using quartz sand grains. Science and Justice, in press

[13] Bennett K.D., Whittington G. \& Edwards K.J. Recent plant nomenclatural changes and pollen morphology in the British Isles. Quaternary Newsletter 73 (1994) 1-6: Quaternary Research Association.

[14] Moore P.D., Webb J.A. \& Collinson M.E. An illustrated guide to pollen analysis. $2^{\text {nd }}$ Ed. Blackwell Scientific, Oxford, 1991.

[15] Stace C. New Flora of the British Isles. Cambridge University Press. Cambridge, 1991. 
[16]Edwards K.J. The cereal pollen record and early agriculture. In: The Beginnings of Agriculture: Milles A., Williams D. \& Gardner N. (Eds): Symposia of the Association for Environmental Archaeology 8: BAR International Series 496 (1989) 113-135.

[17]Anderson S. The identification of wild grasses and cereal pollen. Danmarks Geologiske Undersogelse Arbog 1978: 69-92.

[18]Brunner, H. Identification of Mammal Hair. Inkata Press Melbourne. 1975

[19]Hicks, J. W. Microscopy of Hairs: A Practical Guide and Manual. Federal Bureau of Investigation, Washington, DC, 1977.

[20]Houck, M. M. Hair Bibliography for the Forensic Scientist. Forensic Science Communications Volume 4 Number 1 (2002) (accessed May 2005 http://www.fbi.gov/hq/lab/fsc/backissu/jan2002/houck.htm) 


\section{List of Figures}

Figure 1 photograph of spade 1 (top) and spade 2 (bottom) clearly showing adhering soil

Figure 2 Summary results of initial tests undertaken on soil samples.

Figure 3 Summary results of AAS and Dionex chemical analysis undertaken on soil samples

Figure 4 Summary of mineralogical composition of soil samples

Figure 5 Grain size distribution curves for the soil samples analysed from (left-right top row) the site surface, the site at depth, (left-right middle row) spade 1 back, spade 1 front, (left-right bottom row) spade 2 back and spade 2 front

Figure 6 SEM photograph of distinctive quartz grain exhibiting elongated euhedral overgrowths with terminations

Figure 7 SEM photograph close up of the distinctive quartz grain exhibiting elongated euhedral overgrowths with terminations

Figure 8 SEM photograph of distinctive quartz grain from site at surface soil sample exhibiting elongated euhedral overgrowths with terminations

Figure 9 SEM photograph of distinctive quartz grain taken from spade 1 soil sample exhibiting elongated euhedral overgrowths with terminations

Figure 10 Pollen assemblage diagram for soil taken from spade 1 and 2, the site at surface and the site at depth

Figure 11 Summary results from initial analytical tests on soil samples taken from each exhibit

Figure 12 Mineralogical composition of soil samples taken from each exhibit 
Figure 13 Simple AAS and Dionex chemical analysis derived from soil taken from each exhibit

Figure 14 Grain size distribution curves derived from analysis of sample from (leftright top row) site 1 , site 2, (left-right middle row) left boot composite, right boot composite, (left-right bottom row) right boot 1 and right boot 2 .

Figure 15 SEM photo of predominant quartz grain, with diagenetic sandstone origins and late grain indentors.

Figure 16 SEM photo of grain containing small authigenic euhedral quartz overgrowths produced during diagenesis of the original porous host sandstone 


\begin{tabular}{lccc}
\hline Sample & Colour & Conductivity $(\mu \mathrm{S})$ & $\mathbf{p H}$ \\
\hline Site at surface & 2.5 YR 4/6 & 154.6 & 6.2 \\
Site at depth & 2.5 YR 4/6 & 151.9 & 6.0 \\
Spade 1 front & 2.5 YR 4/6 & 206.0 & 6.7 \\
Spade 1 back & 2.5 YR 4/6 & 218.0 & 7.1 \\
Spade 2 front & 2.5 YR 4/6 & 212.0 & 6.6 \\
Spade 2 back & 2.5 YR 4/6 & 217.0 & 7.0 \\
\hline
\end{tabular}

Figure 2 Summary results of initial tests undertaken on soil samples.

\begin{tabular}{llllllllllllll}
\hline Sample & $\begin{array}{c}\text { \%Organic } \\
\text { Content }\end{array}$ & $\mathrm{CaCO}_{3}$ & $\mathrm{Mg}$ & $\mathrm{Ca}$ & $\mathrm{Fe}$ & $\mathrm{Mn}$ & $\mathrm{Cu}$ & $\mathrm{Pb}$ & $\mathrm{Na}$ & $\mathrm{K}$ & $\mathrm{Cl}$ & $\mathrm{SO}_{4}$ & $\mathrm{NO}_{3}$ \\
& content & & & & & & & & & & & \\
\hline Site at depth & 13.33 & nil & 0.20 & 0.4 & 6.4 & 0.5 & 0.0 & 0.0 & 1.8 & 2.6 & 3.78 & 1.26 & 0.82 \\
Spade 1 front & 20.00 & nil & 0.60 & 0.3 & 7.2 & 0.5 & 0.0 & 0.0 & 1.8 & 2.9 & 1.79 & 1.12 & 0.81 \\
Spade 1 back & 6.67 & nil & 0.50 & 0.3 & 7.7 & 0.3 & 0.0 & 0.0 & 1.8 & 2.4 & 1.50 & 1.09 & 0.72 \\
Spade 2 front & 13.33 & nil & 0.35 & 0.4 & 6.3 & 0.4 & 0.0 & 0.0 & 2.1 & 3.1 & 1.78 & 1.35 & 0.00 \\
Spade 2 back & 13.33 & nil & 0.35 & 0.3 & 6.4 & 0.5 & 0.0 & 0.0 & 2.2 & 2.7 & 2.35 & 1.43 & 0.91 \\
\hline
\end{tabular}

Figure 3 Summary results of AAS and Dionex chemical analysis undertaken on soil samples. 


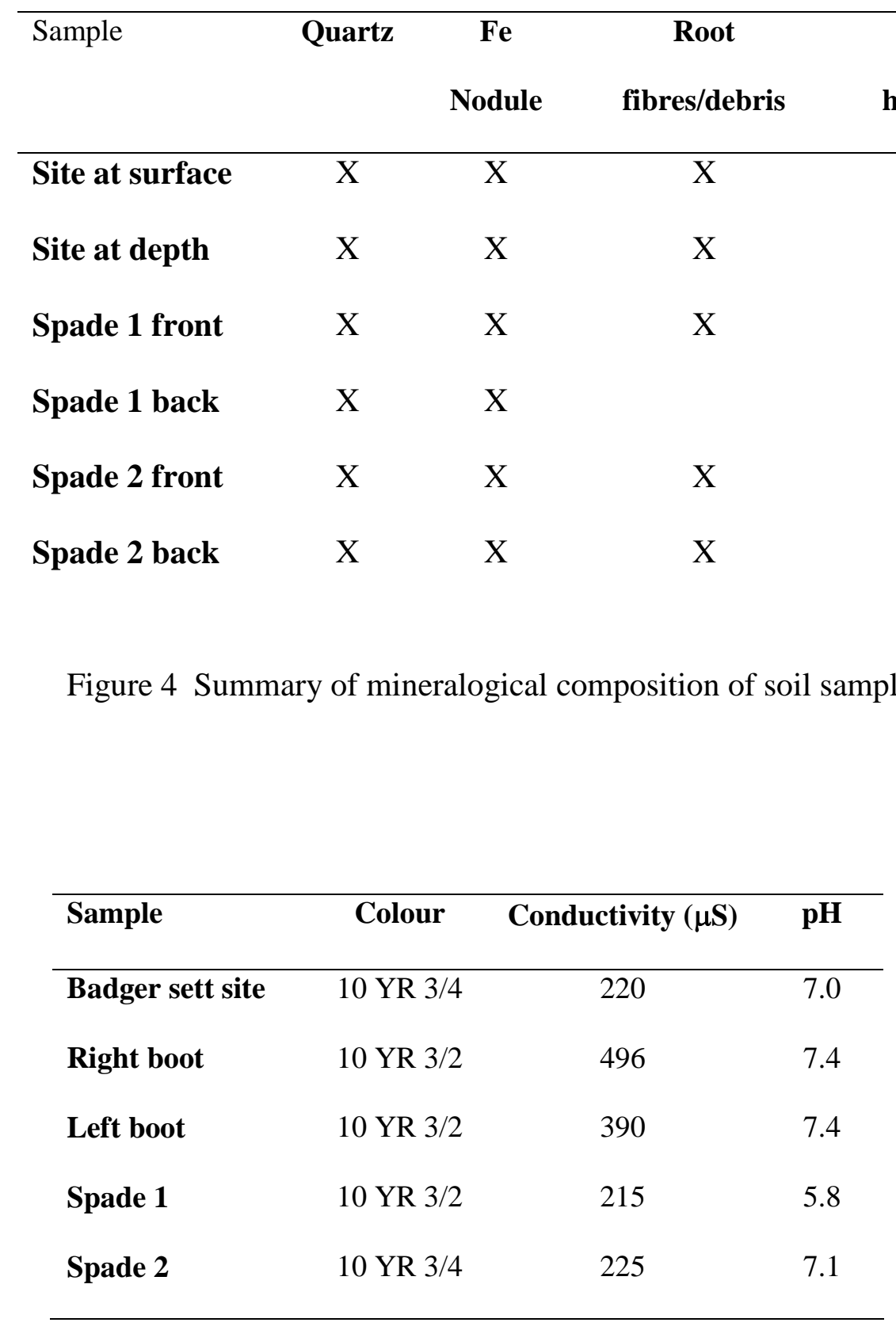

Figure 11 Summary results from initial analytical tests on soil samples taken from each exhibit 


\begin{tabular}{lllllllllll}
\hline Sample & Quartz & Schist & Quartzite & Fe & Meta- & Mica & Calcite & Badger & Plant & Flint/ \\
& & & & Nodule & Igneous & & & hair & Debris & Chert \\
\hline Site & X & X & X & X & X & X & & & X & X \\
Left Boot & X & X & X & X & X & X & X & X & X & X \\
Right Boot & X & X & X & X & X & X & X & X & X & X \\
Spade 1 & X & X & X & X & X & X & & X & X & \\
Spade 2 & X & X & X & X & X & X & & X & X & X
\end{tabular}

Figure 12 Mineralogical composition of soil samples taken from each exhibit

\begin{tabular}{lccccccccccccc}
\hline Sample & Mg & $\mathbf{C a}$ & $\mathrm{Fe}$ & $\mathrm{Mn}$ & $\mathrm{Cu}$ & $\mathrm{Pb}$ & $\mathrm{Na}$ & $\mathrm{K}$ & $\mathrm{Cl}$ & $\mathrm{NO2}$ & $\mathbf{P O 4}$ & $\mathbf{S O 4}$ & $\mathrm{NO3}$ \\
\hline Badger sett site & 3.41 & 0.96 & 19.1 & 0.7 & 0.01 & 0.05 & 1.43 & 3.16 & 1.70 & 0.0 & 0.0 & 0.90 & 6.35 \\
Right boot & 2.60 & 78.4 & 8.5 & 0.6 & 0.00 & 0.10 & 1.10 & 1.60 & 1.90 & 0.0 & 0.1 & 0.80 & 0.60 \\
Left boot & 3.40 & 72.2 & 10.4 & 0.7 & 0.00 & 0.00 & 0.90 & 3.30 & 1.80 & 0.0 & 0.0 & 1.10 & 0.70 \\
Spade 1 & 8.97 & 0.5 & 48.0 & 1.1 & 0.03 & 0.03 & 1.60 & 4.37 & 1.61 & 0.0 & 0.0 & 0.78 & 0.96 \\
Spade 2 & 3.70 & 0.9 & 15.0 & 0.9 & 0.00 & 0.00 & 0.40 & 3.70 & 1.00 & 0.0 & 0.0 & 0.60 & 0.60
\end{tabular}

Figure 13 Summary results of simple AAS and Dionex chemical analysis derived from soil taken from each exhibit 